\title{
LIBS and FTIR-ATR spectroscopy studies of mineral-organic associations in salinized soil
}

\author{
Fei $\mathrm{Ma}^{1}$, Changwen $\mathrm{Du}^{1}$, Yiqiang Zhang ${ }^{2}$, Xuebin $\mathrm{Xu}^{1}$, and Jianmin Zhou ${ }^{1}$ \\ ${ }^{1}$ Institute of Soil Science, Chinese Academy of Sciences \\ ${ }^{2}$ Institute of Water Science, Bayannur
}

June 5, 2020

\begin{abstract}
The direct characterization of the spatial distribution of elements and compound binding of salt-organic associations in soil is imperative for understanding the mechanisms of organic matter decomposition and nutrient release in soil degradation and development processes. Modern spectroscopic techniques provide a feasible method for analysis at the microscale. In this study, mid-infrared attenuated total reflectance spectroscopy (FTIR-ATR) was used to obtain molecular functional group information, laser-induced breakdown spectroscopy (LIBS) was apply to obtain micro-level distribution features of elements in soil, and two-dimensional correlation spectroscopy (2DCOS) analysis was conducted to illustrate the binding combination features of mineral-organic associations in salinized from the Hetao Irrigation District in China. The results showed that the distributions of $\mathrm{Mg}, \mathrm{Ca}, \mathrm{Na}$, and $\mathrm{K}$ were heterogeneous at the micro-level; the spatial distributions of $\mathrm{Mg}$ and $\mathrm{Ca}$ showed a significant correlation $\left(\mathrm{r}=0.90^{* * *}\right)$, while $\mathrm{K}$ displayed a negative correlation with the SOM contents. In soil with lower SOM contents, the elements were distributed at the top of the ablation area and enhanced with the increasing SOM content, which reflected the trends of the SOM layer thickness outside the mineral-organic associations at the micro-level. Furthermore, 2DCOS analysis suggested that the hydrogen bonds in silicate groups were stronger than those of organic functional groups, such as $\mathrm{C}=\mathrm{O} / \mathrm{C}=\mathrm{C}$, when combined with salt-related compounds, and $\mathrm{Mg}, \mathrm{Ca}, \mathrm{Na}$, and $\mathrm{K}$ did not originate from clay mineral compounds in salinized soil, but partially originated from deposited organic associations.
\end{abstract}

\section{ABSTRACT}

The direct characterization of the spatial distribution of elements and compound binding of salt-organic associations in soil is imperative for understanding the mechanisms of organic matter decomposition and nutrient release in soil degradation and development processes. Modern spectroscopic techniques provide a feasible method for analysis at the microscale. In this study, mid-infrared attenuated total reflectance spectroscopy (FTIR-ATR) was used to obtain molecular functional group information, laser-induced breakdown spectroscopy (LIBS) was apply to obtain micro-level distribution features of elements in soil, and two-dimensional correlation spectroscopy (2DCOS) analysis was conducted to illustrate the binding combination features of mineral-organic associations in salinized from the Hetao Irrigation District in China. The results showed that the distributions of $\mathrm{Mg}, \mathrm{Ca}, \mathrm{Na}$, and $\mathrm{K}$ were heterogeneous at the micro-level; the spatial distributions of $\mathrm{Mg}$ and $\mathrm{Ca}$ showed a significant correlation $\left(r=0.90^{* * *}\right)$, while $\mathrm{K}$ displayed a negative correlation with the SOM contents. In soil with lower SOM contents, the elements were distributed at the top of the ablation area and enhanced with the increasing SOM content, which reflected the trends of the SOM layer thickness outside the mineral-organic associations at the micro-level. Furthermore, 2DCOS analysis suggested that the hydrogen bonds in silicate groups were stronger than those of organic functional groups, such as $\mathrm{C}=\mathrm{O} / \mathrm{C}=\mathrm{C}$, when combined with salt-related compounds, and $\mathrm{Mg}, \mathrm{Ca}, \mathrm{Na}$, and $\mathrm{K}$ did not originate from clay mineral compounds in salinized soil, but partially originated from deposited organic associations. 
Keywords: Mineral-organic association, infrared attenuated total reflectance spectroscopy, laser induced breakdown spectroscopy; two-dimensional correlation spectroscopy, spatial distribution, microscale

\section{INTRODUCTION}

Soil salinization adversely affects the physical, chemical, and biological processes of soil, which leads to land degradation and productivity loss (Liu et al., 2018; Sidike et al., 2014; Zovko et al., 2018). The identification of salt-affected soil processes and assessment of the degree of salinization are essential for sustainable agricultural management (Daliakopoulos et al., 2016; Farifteh et al., 2008). The surfaces of minerals and their incorporation into aggregates could physically prevent soil organic matter from extensive decomposition (Lehmann \& Kleber, 2015; J. Xiao et al., 2018). On one side, saline soils have been found to have variable effects on carbon and nitrogen mineralization, which are crucial for the decomposition of organic matter and release of nutrients required to sustain productivity and promote a higher fraction of plant intake in the accumulated organic matter (Daliakopoulos et al., 2016; Pathak \& Rao, 1998; Xiao et al., 2019; Zhang et al., 2019). On the other side, the addition of salts in soil get negative results of soil organic carbon loss as decreased fertility and adversely affects stability of soil aggregates (Singh, 2016; Six et al., 2000). The processes increase dispersion of clay particles as well as soil erosion rates (de la Paix et al., 2013). Therefore, land degradation has recently become a particular focus on the study of soil carbon turnover process (Su et al., 2010) in the context of salt contents soils (Su et al., 2010; J. Xiao et al., 2018), which would be benefit for understanding the formation and stability of organic-mineral complexes in soils.

The Hetao Irrigation District (HID) is a plain located in an arid/semi-arid region that was formed by the Yellow River along its north bank. This area is fertile and densely populated and has been irrigated with water from the Yellow River since ancient times. Irrigated agriculture uses approximately $90 \%$ of the total surface water resources (Wu et al., 2017; Xue \& Ren, 2017). For a considerable time, soil salinization in the area has been aggravated by flood irrigation, increased soil erosion, and water deterioration induced by excessive fertilization (Wu et al., 2017). Meanwhile, soil salinity management relies upon the identification of proper methods and techniques for monitoring and accessing salt-affected soils. Salts are contained in minerals in the form of carbonates, halides, sulfates, and borates (Klein \& Hurlbut Jr, 1999). However, in situ records of the associations of organic and inorganic groups in soils at the microscale have been obstructed due to methodological and analytical limitations.

Recently, spectral-based analytical technologies have been widely used in soil research because they provide in situ , microscale soil information rapidly (Xing et al., 2019). Mid-infrared attenuated total reflectance spectroscopy (ATR) reflects information concerning molecular bonds, such as the modes of molecular functional groups (e.g. stretching/wagging vibration) and clay in minerals, and has been used for soil identification as well as nitrate, clay, sand, and soil carbon measurements (Kira et al., 2014; Linker et al., 2005; Ma et al., 2019). Laser-induced breakdown spectroscopy (LIBS) is an atomic emission spectroscopy technique. As the plasma cools, continuum, ionic, and atomic emissions occur, revealing the elemental composition of the samples. LIBS could obtain microscale information along the vertical scale from each shot (Ilhardt et al., 2019). Therefore, it can be applied to characterize the distribution of soil organic matter, clay minerals, and salt-related elements at the microscale. Additionally, the sensitivity and spatial resolution of LIBS are high (de Oliveira et al., 2019; Kim et al., 2013; Suyanto et al., 2017; Zaytsev et al., 2018).

The two techniques can be used simultaneously to expand upon the current information concerning mineralsorganic association at microscale. Considering the possible overlapping spectral features and the heterogeneity of soil samples, two-dimensional correlation spectroscopy (2DCOS) was employed to present the spectral intensity trends in relation to a perturbation sequence (such as time, temperature, concentration, or spatial distance) over a second dimension (Noda, 2018; Sun et al., 2017; Sun et al., 2019). 2DCOS is typically displayed as contour maps of correlation intensities, as functions of two independent wave numbers/wavelengths. 2DCOS can probe the specific sequence of any subtle spectral changes in response to external perturbations (Noda, 2018; Ruan \& Zhou, 2008; Xu et al., 2018), which can be employed to detect changes in organic and inorganic functional groups and structural relationships in mineral-organic processes along spatial and microscales. 
Thus, we operated the experiments aimed to investigate the minerals-organic complex employing spectral based techniques at microscale, which would provide another sight to understand the relation of mineral and soil organic matter association process in saline soil. The objectives of this study were to: i) investigate the molecular functional groups feature in saline soil using FTIR-ATR spectroscopy; ii) describe the salinizationrelated $\mathrm{Mg}, \mathrm{Ca}, \mathrm{Na}$ and $\mathrm{K}$ element distribution of soil samples using LIBS spectra; and iii) explore the mineral-organic association in saline soils using 2DCOS analysis.

\section{MATERIALS AND METHODS}

\subsection{Soil sample preparation}

Soil samples $(0-20 \mathrm{~cm})$ were collected from Hetao Basin, Inner Mongolia Autonomous Region which is along with the Yellow River in China (latitude 40.719-41.1841N, longitude 107.278-108.7599E) (Fig. 1). The main soil textures are loam, sandy loam, and silt sand (Xue \& Ren, 2017). There is a typical continental arid/semi-arid climate in the area.

\subsection{Determination of soil properties}

The air-dried soil samples were sieved through a 2-mm mesh to remove any plant matter or debris prior to analysis. Prior to spectroscopic measurements, the soil properties of $\mathrm{pH}$ value, SOM contents, the concentration of $\mathrm{Mg}^{2+}, \mathrm{Ca}^{2+}, \mathrm{K}^{+}+\mathrm{Na}^{+}$were determined using conventional chemical methods (Sparks, 1996) and are listed in Table 1.

In this study, six different salt contents with various SOM contents were selected from the above soil samples. The low salt contents were 1.08 and $1.09 \mathrm{~g} / \mathrm{kg}$, the medium salt contents were 9.49 and $9.55 \mathrm{~g} / \mathrm{kg}$, and the high salt contents were 13.31 and $16.10 \mathrm{~g} / \mathrm{kg}$. The corresponding SOM contents were 3.53, 11.38, 8.60, 15.24, 5.78 , and $7.52 \mathrm{~g} / \mathrm{kg}$, respectively.

\subsection{Spectral measurements}

Soil samples were pressed flat against the diamond for improved contact, and a blank reference was used before each sample was scanned. ATR spectra were detected using a handheld attenuated total reflectance infrared Fourier transform spectrometer (Trudefender FT, Thermo Scientific, Waltham, MA, USA). The spectral scanning region was 4000 to $600 \mathrm{~cm}^{-1}$, with a spectral resolution of $4 \mathrm{~cm}^{-1}$. The background noise was subtracted from each scan to correct for atmospheric and instrumental effects.

LIBS spectroscopy was performed using a MobiLIB system (IVEA, Orsay, Essonne, France) with a fourthharmonic Nd: YAG laser operating at $266 \mathrm{~nm}$, with a 5-ns pulse energy of $16 \mathrm{~mJ}$ per pulse, and a highresolution CCD (Sony ILX511B, Tokyo, Japan) spectrometer (Mechelle 5000 Echelle, Andor Technology, Belfast, Northern Ireland) ranging from 200 to $975 \mathrm{~nm}$. Samples were pressed into pellets with a $1 \mathrm{~cm}$ diameter and $0.2 \mathrm{~cm}$ height. The beam diameter at the focal point was $20 \mu \mathrm{m}$. The shot points were $4 \times 4$ matrices with 4 layers of shots at each point (Fig. 2). The ablation spot after each shot was approximately $150 \mu \mathrm{m}$. The distance between two horizontal points was $0.5 \mathrm{~mm}$. As the study was focused on spectra at the micro-level, and the intensity of LIBS spectra can be affected by the shots, we only obtained three shots at the vertical level.

\subsection{Spectral data processing}

The FTIT-ATR and LIBS spectra were pre-processed with baseline correction and a Savitzky-Golay smoothing filter (Savitzky \& Golay, 1964), to reduce the baseline float/noise and improve the signal-to-noise ratio. Matlab software (Mathworks, USA) was used to smooth the data and for all other statistical analyses performed.

The 2DCOS analysis was performed using the method established by Noda and Ozaki (Noda, 2018; Noda \& Ozaki, 2005). The intensity of the synchronous $2 \mathrm{D}$ correlation spectrum, $\Phi\left(\lambda_{1}, \lambda_{2}\right)$, represents the simultaneous or coincidental changes in the spectral intensity at wavenumbers $\lambda_{1}$ and $\lambda_{2}$ with an external perturbation. The peaks on the diagonal line are called auto peaks, while the peaks on the off-diagonal 
line are called crosspeaks. The asynchronous spectrum, $\Psi\left(\lambda_{1}, \lambda_{2}\right)$, represents the out-of-phase or sequential changes in spectral intensities with external perturbation. There is no diagonal peak, but there is a cross peak in off-diagonal areas (Noda, 2018). The red and blue colors on the map represent positive and negative intensities, respectively.

In this study, different salt contents were applied as the external perturbation for the FTIR spectra, while the different vertical detecting points were used as external perturbations for the LIBS spectra. In our study, the spectral synchronous and asynchronous correlation maps were generated from the analysis of the ATR and LIBS spectra, respectively.

\section{Results}

\subsection{FTIR-ATR spectra of soil samples}

The average FTIR-ATR spectra of the soil samples are shown in Fig. 3. The peak at $3610 \mathrm{~cm}^{-1}$ was attributed to the stretching vibration of $\mathrm{O}-\mathrm{H}$ in clay minerals, water, carboxyl groups, and hydroxyl groups (Madejova \& Komadel, 2001; Nayak \& Singh, 2007; Peltre et al., 2014; Xu et al., 2018). The peak at approximately $1660 \mathrm{~cm}^{-1}$ was attributed to the stretching vibrations of $\mathrm{C}=\mathrm{C} / \mathrm{C}=\mathrm{O}$ in amides and aromatics (Madejova \& Komadel, 2001). The stretching vibration of $\mathrm{H}-\mathrm{O}-\mathrm{H}$ from clay bound water has been highlighted for the peak at $1630 \mathrm{~cm}^{-1}$. The peak at $1434 \mathrm{~cm}^{-1}$ has been attributed to the stretching vibration of $\mathrm{CO}_{3}{ }^{2-}$ in carbonate (Soriano-Disla et al., 2013). The stretching vibration of $\mathrm{C}-\mathrm{H}$ in methyls explains the peak spanning 1445-1350 $\mathrm{cm}^{-1}$ (Bernier et al., 2013; Calderón et al., 2013; Movasaghi et al., 2008). The stretching vibration of $\mathrm{Si}-\mathrm{O}$ in silicates (quartz from clay minerals) is present in the $1030-950 \mathrm{~cm}^{-1}$ region (Madejova, 2003). The peak at $915 \mathrm{~cm}^{-1}$ has been attributed to the bending vibration of $\mathrm{Al}-\mathrm{OH}$ from kaolinite and smectite (Madejova \& Komadel, 2001). The stretching vibration of $\mathrm{C}-\mathrm{O}$ from carbonate is visible via the peak at $872 \mathrm{~cm}^{-1}$. The out-of-plane vibrations of amine $\left(\mathrm{NH}_{2}\right)$ explain the peak at $761 \mathrm{~cm}^{-1}$ (Smidt \& Meissl, 2007).

\subsection{LIBS spectra of soil samples}

The average LIBS spectra of the soil samples, from 200 to $1000 \mathrm{~nm}$, are displayed in Fig. 4. The main $\mathrm{Si}, \mathrm{Mg}, \mathrm{Ca}, \mathrm{Na}$, and $\mathrm{K}$ lines were marked according to the National Institute of Standards and Technology (NIST) electronic database (Kramida, 2018). The Ca II (ionic) lines were at 315.89, 317.93, 393.37, 396.85, and $422.67 \mathrm{~nm}$, while the Ca I (atomic) lines were at 558.88, 559.45, and $610.28 \mathrm{~nm}$. The $\mathrm{Mg}$ II (ionic) lines were at 279.55 and $280.27 \mathrm{~nm}$, while the $\mathrm{Mg}$ I (atomic) lines were at 517.27 and $559.45 \mathrm{~nm}$. The Na I lines were at 588.99 and $589.59 \mathrm{~nm}$. The K I lines were at 766.49 and $769.90 \mathrm{~nm}$. The Si line was at $288.15 \mathrm{~nm}$. In general, choosing suitable lines from spectra is an important and challenging task in LIBS analysis. Researchers (Rühlmann et al., 2018) have mentioned that the Ca I line at $422.67 \mathrm{~nm}$ and Ca II lines at 393.37 and $396.85 \mathrm{~nm}$ have been employed for Ca determination detection, but did not show good performance for Ca nutrient quantification in soil because of self-absorbance. Thus, the ionic lines of $\mathrm{Mg} I$ at $517.27 \mathrm{~nm}, \mathrm{Ca}$ I at $558.88 \mathrm{~nm}, \mathrm{Na}$ I at $588.99 \mathrm{~nm}$, and K I at $766.19 \mathrm{~nm}$ were selected for further study.

\subsection{Spatial distribution of metal element contents}

The Mg, Ca, Na, and K lines intensities of six selected samples were obtained from the LIBS spectra (depth in micrometers). The analyzed soil sample properties and calculated correlation coefficients are shown in Fig. 5. Fig. 5a indicates that the SOM was almost uncorrelated with the $\mathrm{pH}(\mathrm{r}=-0.001)$ and was not significantly correlated with the $\mathrm{pH}$, salt, $\mathrm{Ca}^{2+}, \mathrm{Mg}^{2+}, \mathrm{K}^{+}+\mathrm{Na}^{+}$, or CEC contents. Additionally, the $\mathrm{pH}$ was not significantly correlated with the salt content or CEC. The salt content was significantly correlated with the CEC $\left(r=0.98^{* * *}\right), \mathrm{K}^{+}+\mathrm{Na}^{+}\left(r=0.93^{* * *}\right), \mathrm{Mg}^{2+}\left(r=0.73^{* * *}\right)$, and $\mathrm{Ca}^{2+}\left(r=0.42^{* * *}\right)$. The correlation coefficients of $\mathrm{Ca}^{2+}$ with $\mathrm{Mg}^{2+}\left(r=0.43^{* * *}\right)$ and $\mathrm{CEC}\left(r=0.30^{* * *}\right)$ were significant. The $\mathrm{Ca}^{2+}$ contents were neither uncorrelated nor significantly correlated with the $\mathrm{K}^{+}+\mathrm{Na}^{+}$contents $(r=0.09)$, but the $\mathrm{K}^{+}+\mathrm{Na}^{+}$contents were highly significantly correlated with the CEC contents $\left(r=0.96^{* * *}\right)$. The element contents at each ablation spot could not be obtained using the traditional method, owing to technical limitations. However, the LIBS spectral line intensity was positively related with the element contents. Thus, 
the elemental spectra of six selected samples were analyzed, the relationships for which are shown in Fig. 5b. The Mg line intensity showed the highest significant correlation with $\mathrm{Ca}\left(r=0.90^{* * *}\right)$, while the Na line intensity showed a higher correlation coefficient with $\mathrm{K}\left(r=0.77^{* * *}\right)$. The correlation coefficient between $\mathrm{Mg}$ and $\mathrm{K}$ was $0.73^{* * *}$. The spatial distribution maps of $\mathrm{Mg}, \mathrm{Ca}, \mathrm{Na}$, and $\mathrm{K}$ were plotted based on the intensity of the element in Fig. 6.

For the low-salt content samples (columns $\mathrm{C} 1$ and $\mathrm{C} 2$ ), the contents of the four elements differed (C1: salt $1.08 \mathrm{~g} / \mathrm{kg}$ and SOM $3.53 \mathrm{~g} / \mathrm{kg}$; and C2: salt $1.09 \mathrm{~g} / \mathrm{kg}$ and SOM $11.38 \mathrm{~g} / \mathrm{kg}$ ). It was found that Mg, Ca, Na, and $\mathrm{K}$ were mainly distributed in the upper area of each sample in column $\mathrm{C} 1$. However, the distributions of the elements were more even in column $\mathrm{C} 2$. It was noted that the distribution of $\mathrm{Mg}$ was similar to that of $\mathrm{Ca}$, while the distribution of $\mathrm{Na}$ was similar to that of $\mathrm{K}$. The elemental distribution of the medium-salt content samples (column C3: salt $9.49 \mathrm{~g} / \mathrm{kg}$ and SOM $13.80 \mathrm{~g} / \mathrm{kg}$; and C4: $9.55 \mathrm{~g} / \mathrm{kg}$ and SOM 5.60 g/kg) differed from that of the low-salt content samples. When the SOM content of the medium-salt samples was higher $(13.80 \mathrm{~g} / \mathrm{kg}), \mathrm{Mg}, \mathrm{Ca}$, and $\mathrm{K}$ were mainly distributed in the middle and bottom areas of the sample. However, the four elements showed greater distribution trends with the lower SOM contents $(5.60 \mathrm{~g} / \mathrm{kg})$. For high salt-content samples (column C5: salt $10.17 \mathrm{~g} / \mathrm{kg}$ and SOM $13.20 \mathrm{~g} / \mathrm{kg}$; and C6: salt $16.10 \mathrm{~g} / \mathrm{kg}$ and SOM $7.52 \mathrm{~g} / \mathrm{kg}$ ), the four elements were mainly distributed from the top to the middle areas.

\subsection{Two-dimensional correlation spectroscopy (2DCOS) analysis}

To clarify the association between the salt-related elements and SOM, FTIR-ATR was employed. For complicated materials, such as soils, the peaks of the functional groups and molecule bonds located in different submicron domains may be heterogeneous and overlap in 1 D FTIR-ATR spectra. However, the overlapping peaks could have different responses to external perturbations along spatial and micro scales. 2DCOS is built on the classical cross-correlation analysis of spectral intensity variations observed for a sample system of interest under the influence of external perturbations. The concentration of salt was set as the external perturbation.

The generalized two-dimensional synchronous and asynchronous salt content-dependent correlation spectra of the soil samples are plotted in Fig. 7. Auto-peaks appearing at diagonal positions represent the overall susceptibility of the corresponding spectral region to change in spectral intensity, which could be applied to the study system as an external perturbation. In Fig. 7a, the auto-peaks along the diagonal line of the synchronous spectrum, located at $\Phi(1698,1698), \Phi(1548,1548), \Phi(1264,1264)$, and $\Phi(995,995)$ $\mathrm{cm}^{-1}$, have been assigned to the $\mathrm{C}=\mathrm{C}$ stretching in amides and carboxylic acids $\left(1698 \mathrm{~cm}^{-1}\right), \mathrm{N}-\mathrm{H}$ and $\mathrm{C}-\mathrm{N}$ stretching in Amide II $\left(1548 \mathrm{~cm}^{-1}\right), \mathrm{C}-\mathrm{OH}$ and $\mathrm{C}-\mathrm{H}$ of phenols and aromatics $\left(1264 \mathrm{~cm}^{-1}\right)$, and Si-O in clay minerals $\left(995 \mathrm{~cm}^{-1}\right)$. This indicates the components involved in the binding of salt compounds in soil. The main auto-peak, $\Phi(3700,3700) \mathrm{cm}^{-1}$ (Fig. 7c), showed that the $\mathrm{O}-\mathrm{H}$ stretching in clay minerals was involved in the binding of salt-related compounds (Sun et al., 2019). The off-diagonal peaks in the synchronous map exhibited correlated signals (Yu et al., 2012). The negative peaks at $\Phi(995,1548)$ and $\Phi(995,1264) \mathrm{cm}^{-1}$ indicate that the intensity of $\mathrm{Si}-\mathrm{O}$ increased while that of $\mathrm{N}-\mathrm{H} / \mathrm{C}-\mathrm{N}$ and $\mathrm{C}-\mathrm{OH} / \mathrm{C}-\mathrm{H}$ decreased. The negative cross-peaks at $\Phi(2303,3717)$ and $\Phi(2303,3642) \mathrm{cm}^{-1}$ suggest that the intensity of the CO-H stretching in carbohydrates changed directions, to that of $\mathrm{O}-\mathrm{H}$ in clay minerals.

The asynchronous maps were anti-symmetric, which could provide information on the sequential order of functional groups when combined with analysis of the synchronous maps. In the range of $1500-650 \mathrm{~cm}^{-1}(\mathrm{Fig}$. $7 \mathrm{~b})$, there were four main negative peaks at $\Psi(995,1680), \Psi(995,1502), \Psi(995,1451)$, and $\Psi$ (995, 1241). According to Noda and Ozaki's principle (Noda and Ozaki, 2005; Noda, 2018), the sequence of binding affinities of bands with salt-related compounds followed the order: $995-1680 \mathrm{~cm}^{-1}$ and $995-1502 \mathrm{~cm}^{-1}$. This means that the binding of functional groups in soil with salt-related compounds followed the sequence: $\mathrm{Si}-\mathrm{O}>\mathrm{C}=\mathrm{O}$ and $\mathrm{Si}-\mathrm{O}>\mathrm{C}=\mathrm{C}$. Similarly, the negative peaks at $\Psi(893,995)$ and $\Psi(760,995)$ indicated that the binding affinities of $\mathrm{C}-\mathrm{H}\left(893 \mathrm{~cm}^{-1}\right)$ and $\mathrm{NH}_{2}\left(757 \mathrm{~cm}^{-1}\right)$ with salt-related compounds were prior to that of $\mathrm{Si}-\mathrm{O}$. The main off-diagonal peaks distributed in the region of $4000-3000 \mathrm{~cm}^{-1}$ (Fig. $7 \mathrm{~d}$ ) were related to the $\mathrm{O}-\mathrm{H} / \mathrm{N}-\mathrm{H}$ in clay minerals, water, alcohols, phenols, carboxyl groups, and hydroxyl groups (Ma et al., 2019). 


\subsection{FTIR-ATR -LIBS Heterospectral 2DCOS}

In addition, 2D heterospectral correlation maps were used to examine the covariation between bands in FTIR-ATR and LIBS spectra. A molecular and atomic 2D heterospectral correlation map was used, as this could reflect the functional compounds at positive/negative peaks derived from the same origin (Yu et al., 2012).

In the synchronous map (Fig. 8), the negative cross-peaks were located at 995 ( $\mathrm{Si}-\mathrm{O}$ in clay mineral) and $4000-2940 \mathrm{~cm}^{-1}(\mathrm{O}-\mathrm{H}$ in clay mineral) in the FTIR-ATR spectra and at 517 (Mg I), 558 (Ca I), 588 (Na I), and $766(\mathrm{~K} \mathrm{I}) \mathrm{nm}$ in the LIBS spectra.

\section{DISCUSSIONS}

From the element distribution in different soil samples, it can be concluded that i) the distribution trends of $\mathrm{Mg}$ and $\mathrm{Ca}$ were similar in each column, which was consistent with the highly significant correlation between $\mathrm{Mg}$ and $\mathrm{Ca}\left(r=0.90^{* * *}\right)$. The distribution of $\mathrm{Na}$ was partly similar to that of $\mathrm{K}$, with a correlation coefficient of $0.77^{* * *}$. This means that $\mathrm{Mg}$ and Ca might be associated with the minerals in the samples. ii) The color bar on the right in Fig. 6 indicates the uniform intensity for the distribution of each element. It can be seen that $\mathrm{K}$ distributions in the $\mathrm{C} 1$ sample were much higher (intensity value larger than 5500 a.u.) than those of the other samples. Meanwhile, for the samples with the same salt content, the K distribution was higher in the samples with a lower SOM content. For instance, the K distributions in $\mathrm{C} 1$ (SOM $3.53 \mathrm{~g} / \mathrm{kg}$ ), C4 (SOM $5.60 \mathrm{~g} / \mathrm{kg}$ ), and C6 (SOM $7.52 \mathrm{~g} / \mathrm{kg}$ ) were higher. The SOM was negatively correlated with the salt content $(r=-0.07)$ and $\mathrm{K}^{+}+\mathrm{Na}^{+}(r=-0.14)$. iii) The distribution of elements in samples with lower SOM contents (columns C1, C4, and C6) was mainly in the top and middle areas, while the samples with higher SOM contents showed greater distributions of elements in the middle and bottom areas, especially for samples with low and medium salt contents (columns C2 and C3). According to FTIR-PAS spectra, the SOM was a function of depth (Du et al., 2014). The surface layer of SOM in minerals or the exterior of aggregates is the interface between the soil and atmosphere. Alternatively, soil pores and SOM form heterogeneous coatings on the mineral surface via the sorption process (Du et al., 2014; Kleber \& Johnson, 2010). Thus, it could be deduced that the SOM layer outside the mineral aggregate was thinner in soil with a low SOM content, and the laser beam could ablate the mineral after one or two shots. Therefore, $\mathrm{Mg}, \mathrm{Ca}, \mathrm{Na}$, and $\mathrm{K}$ can be detected and described at the top of the microscale (C1, C4, and $\mathrm{C} 6$ ). However, when the SOM layer was thicker, the first laser shot was potentially focused on organic materials. Therefore, the mineral aggregates would be ablated and monitored from the second shot (C2 and $\mathrm{C} 3)$.

As a result of FTIR-ATR Heterospectral 2DCOS maps, microscale differences in the binding of minerals and organic matter could be illustrated, and the intra-hydrogen bonds in silicate groups were stronger than those of organic functional groups, such as $\mathrm{C}=\mathrm{O}$ and $\mathrm{C}=\mathrm{C}$, but weaker than $\mathrm{N}-\mathrm{H}$ and $\mathrm{NH}_{2}$ when combined with salt-related compounds (J. Xiao et al., 2018). Furthermore, from the FTIR-ATR-LIBS Heterospectral 2DCOS maps, it was revealed that the intensities of $\mathrm{Mg}, \mathrm{Ca}$, $\mathrm{Na}$, and $\mathrm{K}$ were not closely associated with the $\mathrm{Si}-\mathrm{O}$ and $\mathrm{O}-\mathrm{H}$ in clay minerals. Therefore, the elements did not originate from clay mineral compounds (Duarte et al., 2015; Forouzangohar et al., 2013; Yu et al., 2012). Additional positive peak correlations between $850-680\left(\mathrm{C}-\mathrm{H}\right.$ bending vibration in aromatics) and $2600-1100 \mathrm{~cm}^{-1}$ (organic functional groups) suggested that $\mathrm{Mg}, \mathrm{Ca}, \mathrm{Na}$, and $\mathrm{K}$ partially originated from organic compounds decomposition (Forouzangohar et al., 2013; Ruan \& Zhou, 2008; Yu et al., 2012) in saline soil in Hetao Area in China.

\section{CONCLUSIONS}

In this study, six soil samples with different salt and SOM contents were analyzed using LIBS, FTIR-ATR, and 2DCOS methods. The main functional groups and salt-related metal elements were analyzed from FTIR-ATR and LIBS spectra. The results revealed that the spatial distribution of $\mathrm{Mg}$ and Ca showed a significant correlation, while $\mathrm{Na}$ and $\mathrm{K}$ also showed a significant correlation. In samples with a lower SOM content, $\mathrm{Mg}, \mathrm{Ca}, \mathrm{Na}$, and $\mathrm{K}$ were distributed at the top of the ablation area. However, the distributions broadened as the SOM content increased. In samples with a lower SOM content, the SOM layer outside of the mineral aggregate was thinner, nd the laser beam could ablate the mineral after one or two shots. The 
hydrogen bonds in silicate groups were stronger than those of organic functional groups, such as $\mathrm{C}=\mathrm{O} / \mathrm{C}=\mathrm{C}$, when combined with salt-related compounds. $\mathrm{Mg}, \mathrm{Ca}, \mathrm{Na}$, and $\mathrm{K}$ were not originally from clay mineral compounds, but did partially originate from organic functional groups.

\section{CONFLICT INTEREST}

The authors declare no potential conflict of interest.

\section{ORCID}

Du Changwen 0000-0002-9064-3581

\section{REFERENCES}

Bernier, M.-H., Levy, G. J., Fine, P., \& Borisover, M. (2013). Organic matter composition in soils irrigated with treated wastewater: FT-IR spectroscopic analysis of bulk soil samples. Geoderma, 209-210 , 233-240. doi:https://doi.org/10.1016/j.geoderma.2013.06.017

Calderón, F., Haddix, M., Conant, R., Magrini-Bair, K., \& Paul, E. (2013). Diffuse-Reflectance FourierTransform Mid-Infrared Spectroscopy as a Method of Characterizing Changes in Soil Organic Matter. Soil Science Society of America Journal 77 (5), 1591-1600. doi:10.2136/sssaj2013.04.0131

Daliakopoulos, I. N., Tsanis, I. K., Koutroulis, A., Kourgialas, N. N., Varouchakis, A. E., Karatzas, G. P., \& Ritsema, C. J. (2016). The threat of soil salinity: A European scale review. Science of The Total Environment, 573 , 727-739. doi:https://doi.org/10.1016/j.scitotenv.2016.08.177

de la Paix, M. J., Lanhai, L., Xi, C., Varenyam, A., Nyongesah, M. J., \& Habiyaremye, G. (2013). Physicochemical properties of saline soils and aeolian dust. Land Degradation \& Development, 24 (6), 539-547. doi:10.1002/ldr.1148

de Oliveira, D. M., Fontes, L. M., \& Pasquini, C. (2019). Comparing laser induced breakdown spectroscopy, near infrared spectroscopy, and their integration for simultaneous multi-elemental determination of micro- and macronutrients in vegetable samples. Analytica Chimica Acta, 1062 , 28-36. doi:https://doi.org/10.1016/j.aca.2019.02.043

Du, C., Goyne, K. W., Miles, R. J., \& Zhou, J. (2014). A 1915-2011 microscale record of soil organic matter under wheat cultivation using FTIR-PAS depth-profiling. Agronomy for Sustainable Development, 34 (4), 803-811. doi:10.1007/s13593-013-0201-6

Duarte, R. M. B. O., Freire, S. M. S. C., \& Duarte, A. C. (2015). Investigating the water-soluble organic functionality of urban aerosols using two-dimensional correlation of solid-state 13C NMR and FTIR spectral data. Atmospheric Environment, 116 , 245-252. doi:https://doi.org/10.1016/j.atmosenv.2015.06.043

Farifteh, J., van der Meer, F., van der Meijde, M., \& Atzberger, C. (2008). Spectral characteristics of salt-affected soils: A laboratory experiment. Geoderma, 145 (3), 196-206. doi:https://doi.org/10.1016/j.geoderma.2008.03.011

Forouzangohar, M., Cozzolino, D., Smernik, R. J., Baldock, J. A., Forrester, S. T., Chittleborough, D. J., \& Kookana, R. S. (2013). Using the power of C-13 NMR to interpret infrared spectra of soil organic matter: A two-dimensional correlation spectroscopy approach.Vibrational Spectroscopy, 66 , 76-82. doi:https://doi.org/10.1016/j.vibspec.2013.02.002

Ilhardt, P. D., Nuñez, J. R., Denis, E. H., Rosnow, J. J., Krogstad, E. J., Renslow, R. S., \& Moran, J. J. (2019). High-resolution elemental mapping of the root-rhizosphere-soil continuum using laser-induced breakdown spectroscopy (LIBS). Soil Biology and Biochemistry, 131 , 119-132. doi:https://doi.org/10.1016/j.soilbio.2018.12.029

Kim, G., Kwak, J., Kim, K.-R., Lee, H., Kim, K.-W., Yang, H., \& Park, K. (2013). Rapid detection of soils contaminated with heavy metals and oils by laser induced breakdown spectroscopy (LIBS). Journal of 
Hazardous Materials, 263 , 754-760. doi:https://doi.org/10.1016/j.jhazmat.2013.10.041

Kira, O., Linker, R., \& Shaviv, A. (2014). A Novel Method Combining FTIR-ATR Spectroscopy and Stable Isotopes to Investigate the Kinetics of Nitrogen Transformations in Soils. Soil Science Society of America Journal, 78 (1), 54. doi:10.2136/sssaj2013.08.0358dgs

Kleber, M., \& Johnson, M. G. (2010). Chapter 3 - Advances in understanding the molecular structure of soil organic matter: implications for interactions in the environment. In D. L. Sparks (Ed.), Advances in Agronomy (Vol. 106, pp. 77-142): Academic Press.

Klein, C., \& Hurlbut Jr, C. J. I., New York. (1999). Manual of Mineralogy. John Wiley \& Sons.

Kramida, A., Ralchenko, Yu., Reader, J. and NIST ASD Team. (2018). NIST Atomic Spectra Database (version 5.6.1),. National Institute of Standards and Technology . doi:https://doi.org/10.18434/T4W30F

Lehmann, J., \& Kleber, M. (2015). The contentious nature of soil organic matter. Nature, 528 , 60. doi:10.1038/nature16069

Linker, R., Shmulevich, I., Kenny, A., \& Shaviv, A. (2005). Soil identification and chemometrics for direct determination of nitrate in soils using FTIR-ATR mid-infrared spectroscopy. Chemosphere, 61 (5), 652-658. doi:10.1016/j.chemosphere.2005.03.034

Liu, W., Xu, X., Lu, F., Cao, J., Li, P., Fu, T., Chen, G., \& Su, Q. (2018). Three-dimensional mapping of soil salinity in the southern coastal area of Laizhou Bay, China. 29 (10), 3772-3782. doi:10.1002/ldr.3077

Ma, F., Du, C. W., Zhou, J. M., \& Shen, Y. Z. (2019). Investigation of soil properties using different techniques of mid-infrared spectroscopy.European Journal of Soil Science, 70 (1), 96-106. doi:10.1111/ejss.12741

Madejová, J. (2003). FTIR techniques in clay mineral studies. Vibrational Spectroscopy, 31 (1), 1-10. doi:https://doi.org/10.1016/S0924-2031(02)00065-6

Madejova, J., \& Komadel, P. (2001). Baseline studies of the clay minerals society source clays: infrared methods. Clays and Clay Minerals, 49 (5), 372-373.

Movasaghi, Z., Rehman, S., \& ur Rehman, D. I. (2008). Fourier Transform Infrared (FTIR) Spectroscopy of Biological Tissues. Applied Spectroscopy Reviews, 43 (2), 134-179. doi:10.1080/05704920701829043

Nayak, P. S., \& Singh, B. K. (2007). Instrumental characterization of clay by XRF, XRD and FTIR. Bulletin of Materials Science, 30 (3), 235-238. doi:10.1007/s12034-007-0042-5

Noda, I. (2018). Advances in Two-Dimensional Correlation Spectroscopy (2DCOS). In Frontiers and Advances in Molecular Spectroscopy (pp. 47-75).

Noda, I., \& Ozaki, Y. (2005). Two-dimensional correlation spectroscopy: applications in vibrational and optical spectroscopy : John Wiley \& Sons.

Pathak, H., \& Rao, D. L. N. (1998). Carbon and nitrogen mineralization from added organic matter in saline and alkali soils. Soil Biology and Biochemistry, 30 (6), 695-702. doi:https://doi.org/10.1016/S00380717(97)00208-3

Peltre, C., Bruun, S., Du, C., Thomsen, I. K., \& Jensen, L. S. (2014). Assessing soil constituents and labile soil organic carbon by mid-infrared photoacoustic spectroscopy. Soil Biology and Biochemistry, 77, 41-50. doi:https://doi.org/10.1016/j.soilbio.2014.06.022

Ruan, Q.-X., \& Zhou, P. (2008). Sodium ion effect on silk fibroin conformation characterized by solidstate NMR and generalized 2D NMR-NMR correlation. Journal of Molecular Structure, 883-884, 85-90. doi:https://doi.org/10.1016/j.molstruc.2007.11.055

Rühlmann, M., Büchele, D., Ostermann, M., Bald, I., \& Schmid, T. (2018). Challenges in the quantification of nutrients in soils using laser-induced breakdown spectroscopy - A case study with calcium.Spectrochimica 
Acta Part B: Atomic Spectroscopy, 146 , 115-121. doi:https://doi.org/10.1016/j.sab.2018.05.003

Savitzky, A., \& Golay, M. J. E. (1964). Smoothing and Differentiation of Data by Simplified Least Squares Procedures. Analytical Chemistry, 36 (8), 1627-1639. doi:10.1021/ac60214a047

Sidike, A., Zhao, S., \& Wen, Y. (2014). Estimating soil salinity in Pingluo County of China using QuickBird data and soil reflectance spectra. International Journal of Applied Earth Observation and Geoinformation, 26 , 156-175. doi:https://doi.org/10.1016/j.jag.2013.06.002

Singh, K. (2016). Microbial and Enzyme Activities of Saline and Sodic Soils. Land Degradation 63 Development, 27 (3), 706-718. doi:10.1002/ldr.2385

Six, J., Paustian, K., Elliott, E. T., \& Combrink, C. (2000). Soil Structure and Organic Matter I. Distribution of Aggregate-Size Classes and Aggregate-Associated Carbon. Soil Science Society of America Journal, 64 (2), 681-689. doi:10.2136/sssaj2000.642681x

Smidt, E., \& Meissl, K. (2007). The applicability of Fourier transform infrared (FT-IR) spectroscopy in waste management. Waste Management, 27 (2), 268-276. doi:https://doi.org/10.1016/j.wasman.2006.01.016

Soriano-Disla, J. M., Janik, L. J., Viscarra Rossel, R. A., Macdonald, L. M., \& McLaughlin, M. J. (2013). The Performance of Visible, Near-, and Mid-Infrared Reflectance Spectroscopy for Prediction of Soil Physical, Chemical, and Biological Properties. Applied Spectroscopy Reviews, 49 (2), 139-186. doi:10.1080/05704928.2013.811081

Sparks, D. L. (1996). Methods of Soil Analysis. Part 3, SSSA Book Series, Madison.

Su, Y. Z., Wang, X. F., Yang, R., \& Lee, J. (2010). Effects of sandy desertified land rehabilitation on soil carbon sequestration and aggregation in an arid region in China. Journal of Environmental Management, 91 (11), 2109-2116. doi:https://doi.org/10.1016/j.jenvman.2009.12.014

Sun, F., Polizzotto, M. L., Guan, D., Wu, J., Shen, Q., Ran, W., Wang, B., \& Yu, G. (2017). Exploring the interactions and binding sites between $\mathrm{Cd}$ and functional groups in soil using two-dimensional correlation spectroscopy and synchrotron radiation based spectromicroscopies. Journal of Hazardous Materials, 326 , 18-25. doi:https://doi.org/10.1016/j.jhazmat.2016.12.019

Sun, F., Yu, G., Polizzotto, M. L., Ran, W., \& Shen, Q. (2019). Toward understanding the binding of Zn in soils by two-dimensional correlation spectroscopy and synchrotron-radiation-based spectromicroscopies.Geoderma, 337 , 238-245. doi:https://doi.org/10.1016/j.geoderma.2018.09.032

Suyanto, H., Lie, T. J., Kurniawan, K. H., Kagawa, K., \& Tjia, M. O. (2017). Practical soil analysis by laser induced breakdown spectroscopy employing subtarget supported micro mesh as a powder sample holder.Spectrochimica Acta Part B: Atomic Spectroscopy, 137 , 59-63. doi:10.1016/j.sab.2017.09.013

Wu, Y., Shi, X., Li, C., Zhao, S., Pen, F., \& Green, T. R. (2017). Simulation of Hydrology and Nutrient Transport in the Hetao Irrigation District, Inner Mongolia, China. 9 (3), 169.

Xiao, J., Wen, Y., Yu, G., \& Dou, S. (2018). Strategy for Microscale Characterization of Soil Mineral-Organic Associations by Synchrotron-Radiation-Based FTIR Technology. Soil Science Society of America Journal, 82 (6). doi:10.2136/sssaj2018.05.0211

Xiao, Y., Zhao, G., Li, T., Zhou, X., \& Li, J. (2019). Soil salinization of cultivated land in Shandong Province, China-Dynamics during the past 40 years. Land Degradation $\mathscr{E}$ Development, 30 (4), 426-436. doi:10.1002/ldr.3236

Xing, Z., Tian, K., Du, C., Li, C., Zhou, J., \& Chen, Z. (2019). Agricultural soil characterization by FTIR spectroscopy at micrometer scales: Depth profiling by photoacoustic spectroscopy. Geoderma, 335 , 94-103. doi:https://doi.org/10.1016/j.geoderma.2018.08.003 
Xu, Y., Ozaki, Y., Noda, I., \& Jung, Y. M. (2018). Chapter 10 - 2D Correlation Spectroscopy and Its Application in Vibrational and Optical Spectroscopy. In V. P. Gupta (Ed.), Molecular and Laser Spectroscopy (pp. 217-240): Elsevier.

Xue, J., \& Ren, L. (2017). Assessing water productivity in the Hetao Irrigation District in Inner Mongolia by an agro-hydrological model.Irrigation Science, 35 (4), 357-382. doi:10.1007/s00271-017-0542-z

Yu, G., Wu, M., Wei, G., Luo, Y., Ran, W., Wang, B., Zhang, J., \& Shen, Q. (2012). Binding of Organic Ligands with $\mathrm{Al}$ (III) in Dissolved Organic Matter from Soil: Implications for Soil Organic Carbon Storage.Environmental Science $\&$ Technology, 46 (11), 6102-6109. doi:10.1021/es3002212

Zaytsev, S. M., Krylov, I. N., Popov, A. M., Zorov, N. B., \& Labutin, T. A. (2018). Accuracy enhancement of a multivariate calibration for lead determination in soils by laser induced breakdown spectroscopy.Spectrochimica Acta Part B: Atomic Spectroscopy, 140 , 65-72. doi:10.1016/j.sab.2017.12.005

Zhang, H., Xiang, Y., Irving, L. J., Li, Q., \& Zhou, D. (2019). Nitrogen addition can improve seedling establishment of N-sensitive species in degraded saline soils. Land Degradation 85 Development, 30 (2), 119-127. doi:10.1002/ldr.3195

Zovko, M., Romić, D., Colombo, C., Di Iorio, E., Romić, M., Buttafuoco, G., \& Castrignanò, A. (2018). A geostatistical Vis-NIR spectroscopy index to assess the incipient soil salinization in the Neretva River valley, Croatia. Geoderma, 332, 60-72. doi:https://doi.org/10.1016/j.geoderma.2018.07.005

TABLE 1 Soil properties of the total soil samples

\begin{tabular}{|c|c|c|c|c|}
\hline & Mean & Medium & Standard Deviation & Range \\
\hline $\mathrm{SOM} \mathrm{g} / \mathrm{kg}$ & 10.49 & 10.47 & 3.35 & $3.36-17.70$ \\
\hline $\mathrm{pH}$ & 8.16 & 8.19 & 0.24 & $7.58-9.55$ \\
\hline Salt $\mathrm{g} / \mathrm{kg}$ & 2.42 & 1.62 & 2.43 & $0.84-17.11$ \\
\hline $\mathrm{Ca}^{2+} \mathrm{mg} / \mathrm{kg}$ & 144.89 & 100.2 & 195.92 & $40.08-2284.48$ \\
\hline $\mathrm{Mg}^{2+} \mathrm{mg} / \mathrm{kg}$ & 78.33 & 48.6 & 105.69 & $12.15-911.25$ \\
\hline $\mathrm{K}^{+}+\mathrm{Na}^{+} \mathrm{mg} / \mathrm{kg}$ & 527.08 & 299.00 & 740.34 & $115.00-5945.50$ \\
\hline $\mathrm{CEC} \mathrm{cmol} / \mathrm{kg}$ & 0.71 & 0.45 & 0.81 & $0.32-5.27$ \\
\hline
\end{tabular}

\section{Figure Legends}

FIG. 1 Geographical distribution of the soil sample sites

FIG. 2 Laser shot points on a soil sample pellet

FIG. 3 Average FTIR-ATR spectra of the soil samples

FIG. 4 Average LIBS spectra of the soil samples

FIG. 5 (a) Correlations between the properties of the soil samples. (b) Correlations between the intensities of the LIBS spectra of six selected samples.

FIG. 6 Spatial distribution of $\mathrm{Mg}, \mathrm{Ca}, \mathrm{Na}$, and $\mathrm{K}$ based on the LIBS spectra intensity in an area of $2 \times 2$ $\mathrm{mm}$, with the depth in micrometers. Column $\mathrm{C}$ represents the distribution of elements in each sample. C1: salt $1.08 \mathrm{~g} / \mathrm{kg}$ and SOM $3.53 \mathrm{~g} / \mathrm{kg}$; C2: salt $1.09 \mathrm{~g} / \mathrm{kg}$ and SOM $11.38 \mathrm{~g} / \mathrm{kg}$; C3: salt $9.49 \mathrm{~g} / \mathrm{kg}$ and SOM $13.80 \mathrm{~g} / \mathrm{kg}$; C4: $9.55 \mathrm{~g} / \mathrm{kg}$ and SOM $5.60 \mathrm{~g} / \mathrm{kg}$; C5: salt $10.17 \mathrm{~g} / \mathrm{kg}$ and SOM $13.20 \mathrm{~g} / \mathrm{kg}$; and C6: salt 16.10 $\mathrm{g} / \mathrm{kg}$ and SOM $7.52 \mathrm{~g} / \mathrm{kg}$

FIG. 7 Synchronous (a, c) and asynchronous (b, d) FTIR-ATR 2D salt content-dependent correlation maps generated from $2500-650 \mathrm{~cm}^{-1}$ and $4000-2000 \mathrm{~cm}^{-1}$, respectively 
FIG. 8 Synchronous (a) and asynchronous (b) FTIR-ATR -LIBS Hetero 2DCOS generated from salt content-dependent maps. Red and blue colors represent positive and negative correlations, respectively. The darker color indicates a stronger correlation than the lighter color

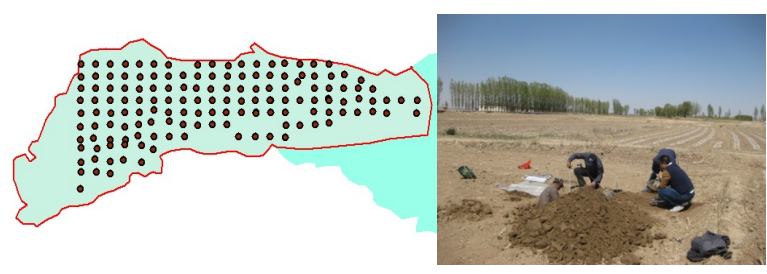

FIG. 1 Geographical distribution of the soil sample sites 


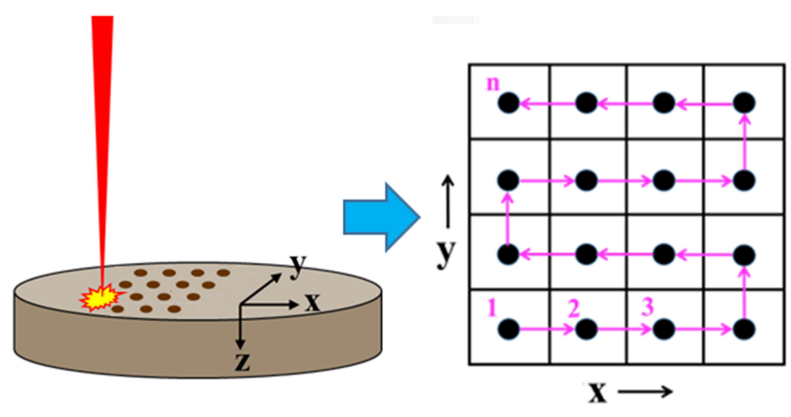

FIG. 2 Laser shot points on a soil sample pellet 


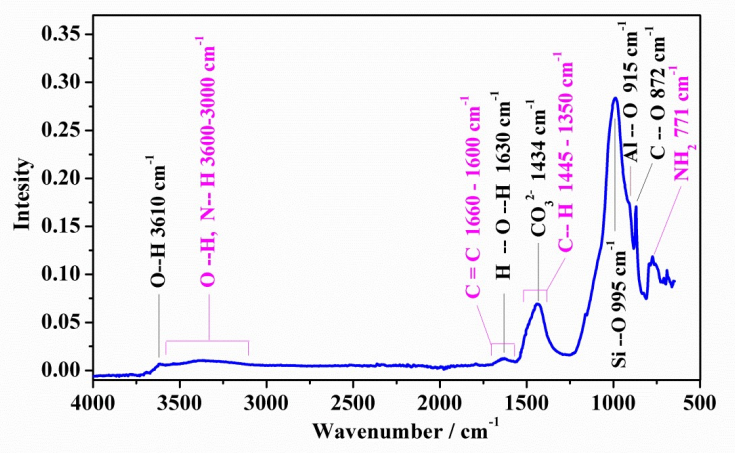

FIG. 3 Average FTIR-ATR spectra of the soil samples 


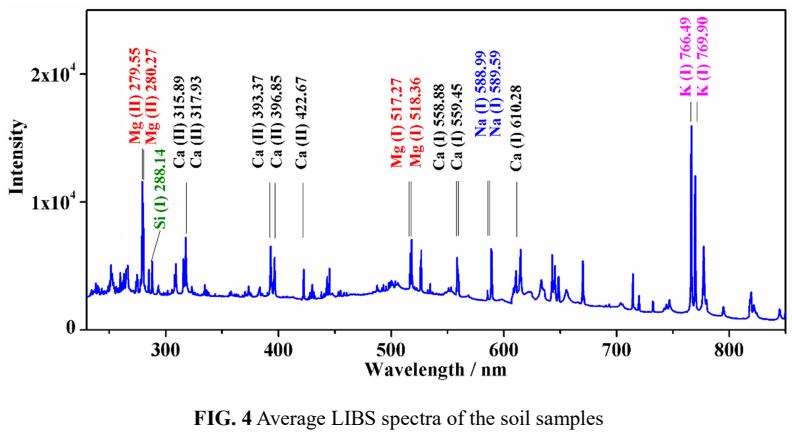




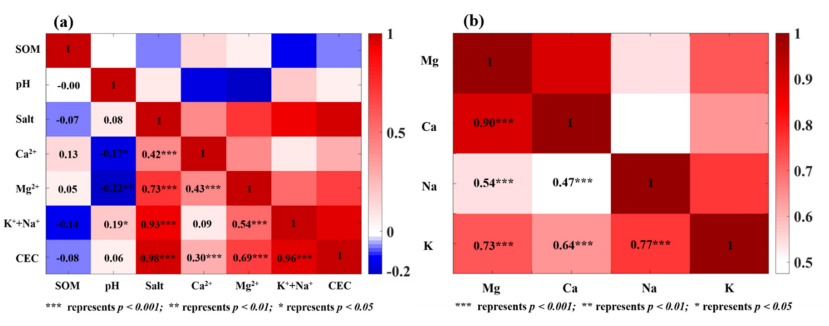

FIG. 5 (a) Correlations between the properties of the soil samples. (b) Correlations between

the intensities of the LIBS spectra of six selected samples 


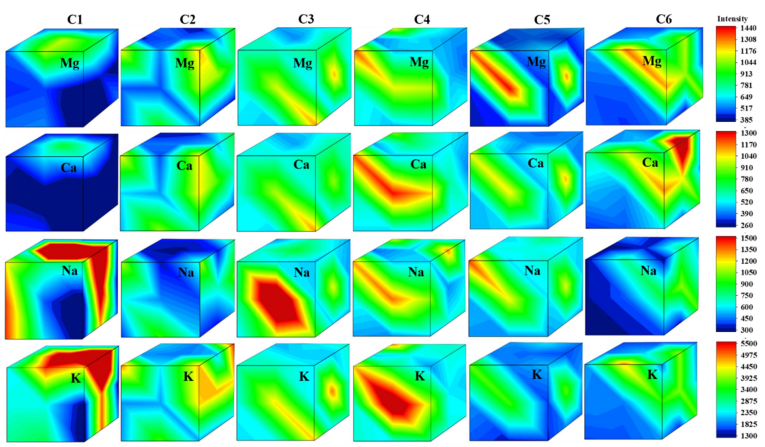

FIG. 6 Spatial distributions of $\mathrm{Mg}, \mathrm{Ca}, \mathrm{Na}$, and $\mathrm{K}$ at micrometers. Column $\mathrm{C}$ represents the distribution of elements in each sample. C1: salt $1.08 \mathrm{~g} / \mathrm{kg}$ and SOM $3.53 \mathrm{~g} / \mathrm{kg}$; C2: salt 1.09 $\mathrm{g} / \mathrm{kg}$ and SOM $11.38 \mathrm{~g} / \mathrm{kg} ; \mathrm{C} 3$ : salt $9.49 \mathrm{~g} / \mathrm{kg}$ and SOM $13.80 \mathrm{~g} / \mathrm{kg} ; \mathrm{C} 4: 9.55 \mathrm{~g} / \mathrm{kg}$ and SOM $5.60 \mathrm{~g} / \mathrm{kg}$; C5: salt $10.17 \mathrm{~g} / \mathrm{kg}$ and SOM $13.20 \mathrm{~g} / \mathrm{kg}$; and C6: salt $16.10 \mathrm{~g} / \mathrm{kg}$ and SOM 7.52 $\mathrm{g} / \mathrm{kg}$ 


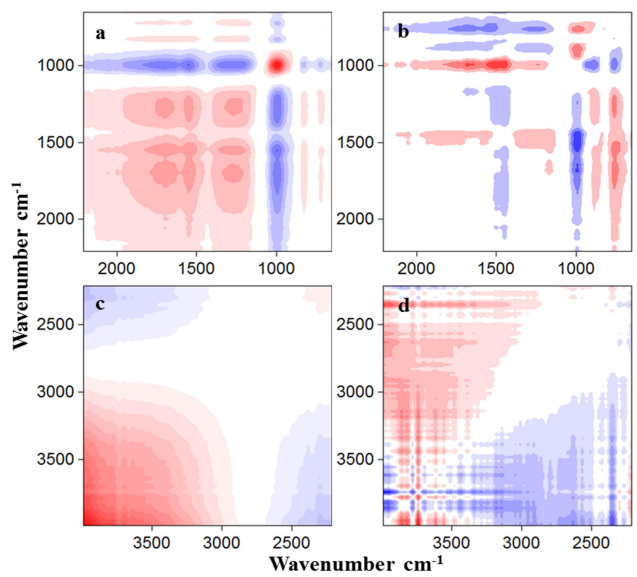

FIG. 7 Synchronous (a, c) and asynchronous (b, d) FTIR-ATR 2D salt content-dependent

correlation maps generated from $2500-650 \mathrm{~cm}^{-1}$ and $4000-2000 \mathrm{~cm}^{-1}$, respectively 


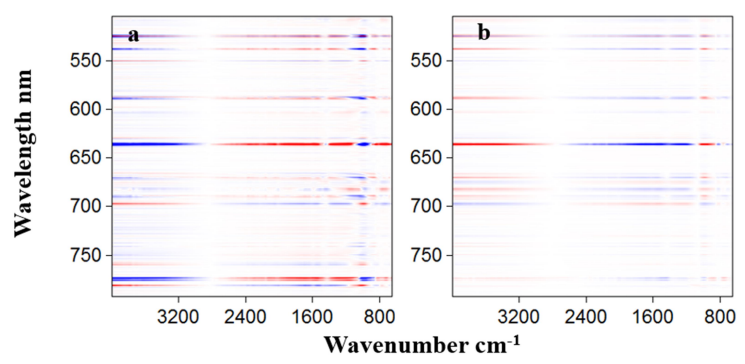

FIG. 8 Synchronous (a) and asynchronous (b) FTIR-ATR -LIBS Hetero 2DCOS generated from salt content-dependent maps. Red and blue colors represent positive and negative correlations, respectively. The darker color indicates a stronger correlation than the lighter color 